\title{
SORG Algorithm to Predict 3- and 12-month Survival in Metastatic Spinal Disease: A Cross-Sectional Population-Based Retrospective Study.
}

\section{Gregory Zegarek}

University Hospital of Geneva

\section{Enrico Tessitore}

University Hospital of Geneva

\section{Etienne Chaboudez}

University Hospital of Geneva

\section{Aria Nouri}

University Hospital of Geneva

\section{Karl Schaller}

University Hospital of Geneva

Renato Gondar ( $\square$ renatojesus.almeidagondar@hcuge.ch )

University Hospital of Geneva

\section{Research Article}

Keywords: SORG, survival prediction, spinal metastases, NOMS algorithm, separation surgery, hybrid therapy, outcome measures

Posted Date: November 17th, 2021

DOl: https://doi.org/10.21203/rs.3.rs-960987/v1

License: (c) (i) This work is licensed under a Creative Commons Attribution 4.0 International License. Read Full License

Version of Record: A version of this preprint was published at Brain and Spine on January 1st, 2021. See the published version at https://doi.org/10.1016/j.bas.2021.100122. 
Article

SORG algorithm to predict 3- and 12-month survival in metastatic spinal disease: A Cross-Sectional Population-Based Retrospective Study.

Gregory Zegarek 1, Enrico Tessitore 1, Etienne Chaboudez 1, Aria Nouri 1, Karl Schaller ${ }^{1}$, and Renato Gondar 1*

${ }^{1}$ Department of Neurosurgery, Geneva University Hospitals, University of Geneva, Geneva, Switzerland; neurch.rachis@hcuge.ch

* Correspondence: renatojesus.almeidagondar@hcuge.ch

Correspondence Addresses:

Gregory.zegarek@hcuge.ch

Enrico.tessitore@hcuge.ch

Chaboudezetienne@gmail.com

Aria.nouri@hcuge.ch

Karl.schaller@hcuge.ch

Renatojesus.almeidagondar@hcuge.ch 


\begin{abstract}
In this study, we recruited 40 patients with spinal metastatic disease who were operated at Geneva University Hospitals by the Neurosurgery or Orthopedic teams between the years of 2015 and 2020. We did an ROC analysis in order to determine the accuracy of the SORG ML algorithm and nomogram versus the Tokuhashi Original and Revised Scores. The analysis of data of our independent cohort shows a clear advantage in terms of predictive ability of the SORG ML algorithm and nomogram in comparison with the Tokuhashi scores. The SORG ML had an AUC of 0.87 for 90 -days and 0.85 for 1 -year. The SORG Nomogram showed a predictive ability at 90-days and 1-year with AUC's of 0.87 and 0.76 respectively. These results showed excellent discriminative ability as compared with the Tokuhashi Original Score which achieved AUC's of 0.70 and 0.69 and the Tokuhashi Revised Score which had AUC's of 0.65 and 0.71 for 3-month and 1-year respectively. The predictive ability of the SORG ML algorithm and nomogram were superior to currently used preoperative survival estimation scores for spinal metastatic disease.
\end{abstract}

Keywords: SORG; survival prediction; spinal metastases; NOMS algorithm; separation surgery; hybrid therapy; outcome measures. 


\section{Introduction}

Epidemiological data of metastatic spinal disease remain difficult to estimate as spinal metastases may be underdiagnosed if mild and asymptomatic, or missed due to short life expectancy as a result of systemic disease burden. Nevertheless, it is thought that $5-10 \%$ of cancer patients suffer from spinal metastasis[1,2], with at least half of these presenting a metastatic epidural invasion or even spinal cord compression[2-4,1] and approximately $10 \%$ eventually benefitting from spinal surgery.[2-4,1,5]

To determine the optimal treatment for each individual patient while taking into account all the important factors influencing such decision-making, several decision frameworks were proposed in recent years. Among these, NOMS (neurologic, oncologic, mechanical and systemic)[6] is probably the most used and reproducible worldwide as it overcomes the shortcomings of fixed algorithmic scoring systems. Thus, clinicians are asked to balance acute neurological status and risk of mechanical instability against life-expectancy and risk of treatment-related morbidity and mortality.[7,5,8,4] Added to these previous considerations, recent evidence also proposes more aggressive treatment even if life expectancy is inferior to three months for patients with a good baseline condition.[9] All in all, a proper estimation of postoperative survival prediction plays an important role in tumor boards' decision and thus should strive to be as accurate as possible.

To the moment, there's no standardized estimation tool for overall postoperative prognosis. Nater et al.[10] performed a full external validation of eight scores (Tokuhashi,[11] Tomita,[12] van der Linden,[13] and Bollen[14] among others) and concluded that calibration was poor overall. It is suggested that clinicians should use these tools with caution, especially if they are applied in a population different from the development population. More recently, the SORG (Skeletal Oncology Research Group) nomogram (Figure 1)[15,16], which was developed with patients from Massachusetts General Hospital and Brigham and Women's Hospital, has proven to be a promising prognostic tool for surgically treated spinal metastatic patients. This tool still lacks external validation using an international independent data set performed by a different group of investigators in order to be established in clinical practice (external validations were made in high-volume hospital centers in North America, such as The Johns Hopkins Hospital[17] and Memorial Sloan Kettering Cancer Center[18]). Furthermore, Ahmed et al.[19] found that the SORG Nomogram (Figure 1) demonstrated the highest accuracy at predicting 30-day and 90-day survival, whereas the original Tokuhashi[11] was the most accurate at predicting 365-day survival. 


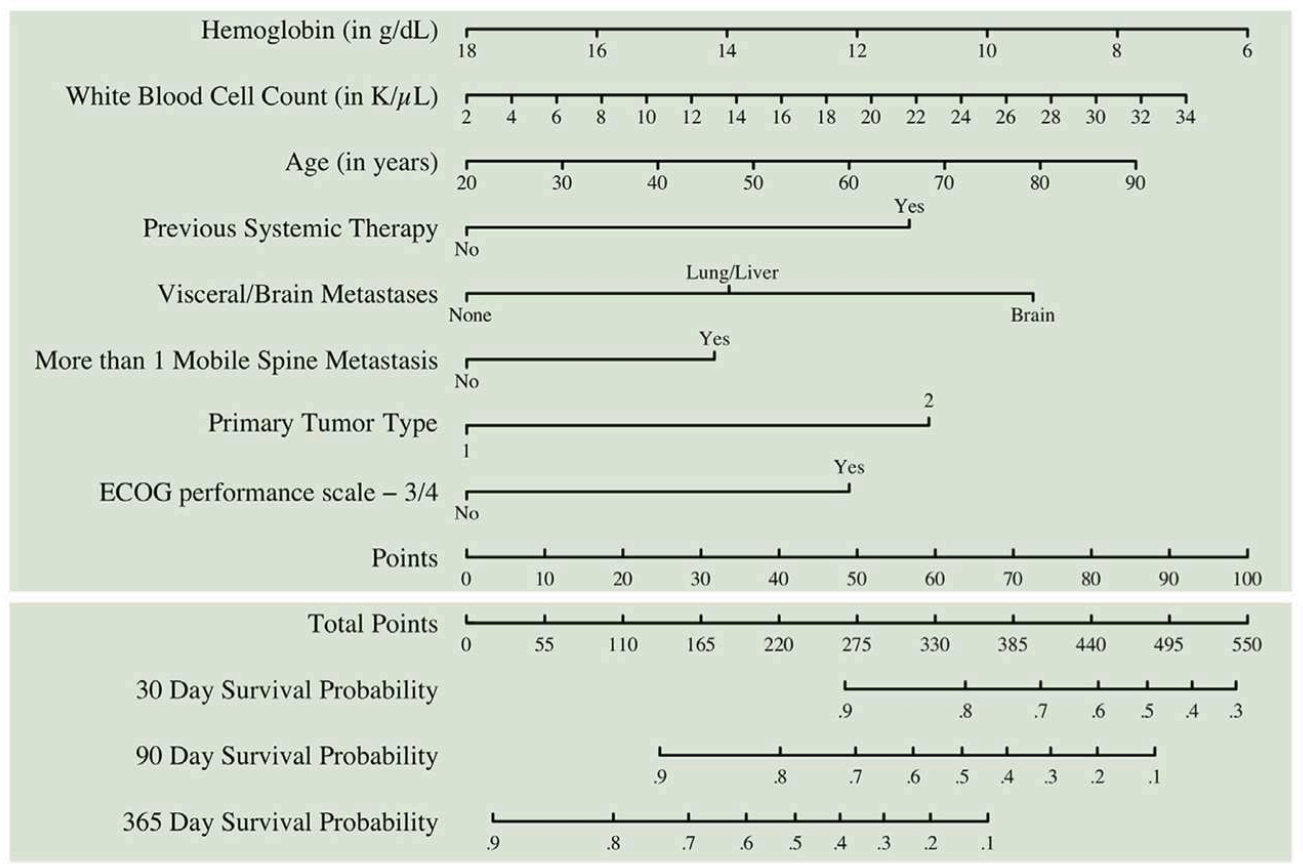

Figure 1:[16,20] The SORG nomogram: to be used for patients with operable spinal metastatic disease. For each parameter, the point on the corresponding axis is determined and a vertical line is drawn downward so that the number of points given (eg, a patient with a preoperative hemoglobin of $10 \mathrm{~g} / \mathrm{dL}$ will receive between 65 and 70 points) may be read. This process is repeated for every parameter. The sum of points can be located on the total points axis, from which a vertical line is drawn downward so that the 30-, 90-, and 365-day survival probability may be read. Primary tumor type 1 = lymphoma, breast cancer, multiple myeloma, kidney cancer, prostate cancer, or thyroid cancer. Primary tumor type $2=$ lung cancer, colon cancer, rectal cancer, bladder cancer, esophageal cancer, liver cancer, melanoma, gastric cancer, or other cancers.

*Reproduced with permission of Paulino Pereira NR, J Surg Oncol 115 (8):1019-1027. doi:10.1002/jso.24620.

The SORG classic model was published as an online application(Table 1),[21] incorporating new additional parameters (alkaline phosphatase, neutrophil-to-lymphocyte ratio, platelet-to-lymphocyte ratio) and still seeks for validation in large patient samples from a more international setting. The aim of this study is to assess whether this SORG machine-learning (SORG ML) algorithm is able to: (1) provide decisional support and to match decisions taken by expert multidisciplinary teams to operate or not spinal metastasis in an international cohort distinct from the development population; (2) discriminate patients that could benefit from surgical care despite the presumption of a life expectancy shorter than three-months (based on systemic disease burden). 


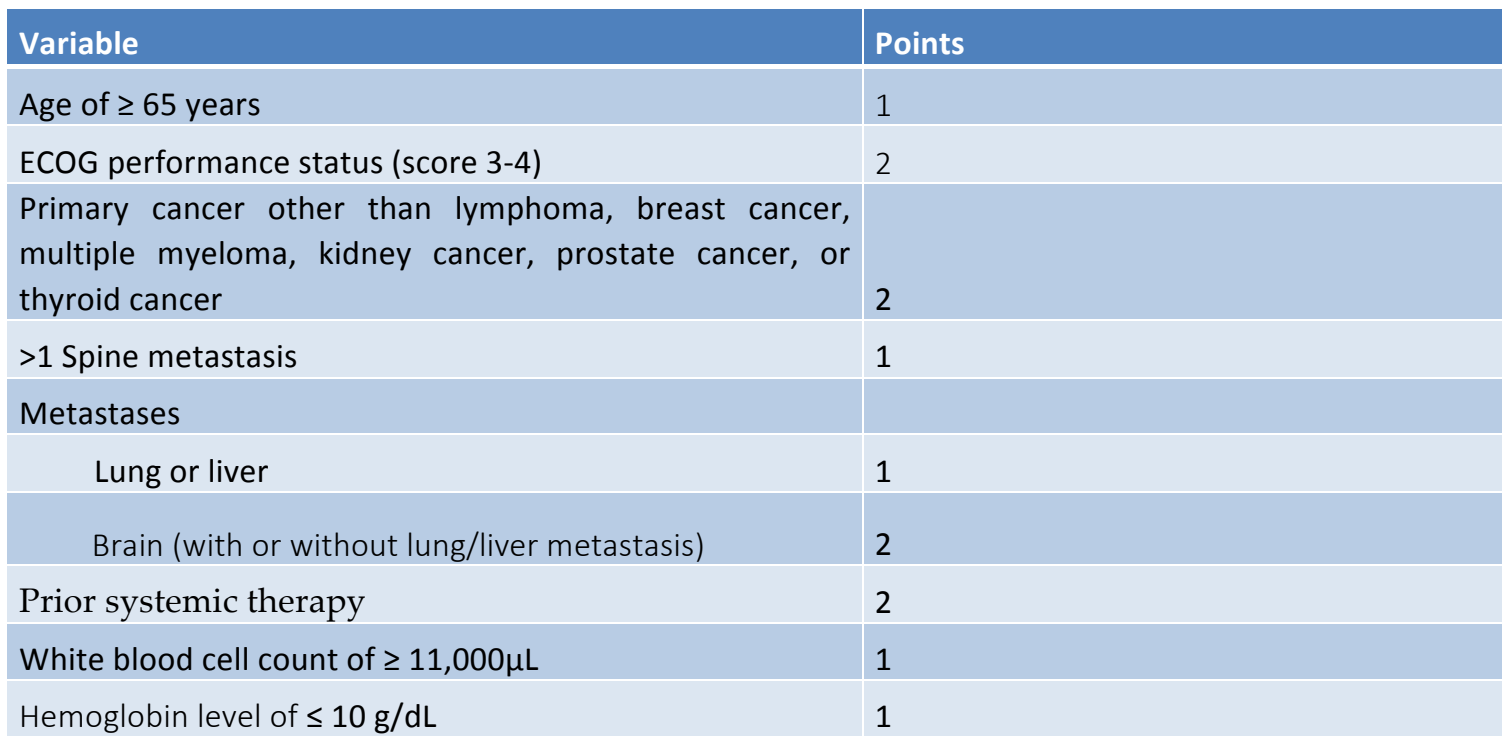

\begin{tabular}{|c|l|}
\hline Prognostic Groups & Probability of Survival \\
\hline \begin{tabular}{|l|} 
Good prognosis (score of $0-2$ points) \\
\hline 30 days
\end{tabular} & $0.99(0.98$ to 0.99$)$ \\
\hline 90 days & $0.94(0.90$ to 0.98$)$ \\
\hline 365 days & $0.81(0.74$ to 0.88$)$ \\
\hline Intermediate prognosis (score of 3-4 points) & \\
\hline 30 days & $0.96(0.94$ to 0.99$)$ \\
\hline 90 days & $0.85(0.80$ to 0.90$)$ \\
\hline 365 days & $0.62(0.56$ to 0.69$)$ \\
\hline Poor prognosis (score of 5-12 points) & \\
\hline 30 days & $0.86(0.82$ to 0.90$)$ \\
\hline 90 days & $0.63(0.58$ to 0.69$)$ \\
\hline 365 days & $0.28(0.23$ to 0.33$)$ \\
\hline
\end{tabular}

*The values are given as the $\mathrm{HR}$, with the $95 \% \mathrm{CI}$ in parentheses.

Table 1:[16] Predictors/variables composing the SORG classic algorithm and corresponding postoperative survival probability. 


\section{Materials and Methods}

Our hypothesis is that, as partially demonstrated previously, $[16,20,18,19]$ the SORG nomogram and ML are better predictive tools than the Tokuhashi Original or Revised scores for spinal metastatic disease survival at 3 months and 1 year. This international validation followed the Transparent Reporting of a Multivariable Prediction Model for Individual Prognosis or Diagnosis (TRIPOD).[22] All methods were performed in accordance with the relevant guidelines and regulations according to our institutional review board.

\section{Inclusion/Exclusion Criteria}

All patients diagnosed with spinal metastasis between January 2015 and May 2020 were prospectively and consecutively recruited and discussed in our multidisciplinary tumor board. Among these, the following inclusion criteria were applied: 1) adult patients between the ages of 18 and 90 at the time of surgery; 2) included patients had surgery for a metastatic spine lesion; 3) primary tumor histology was confirmed by pathology; 4) availability of electronic medical records (EMR) with imaging, operative notes, and laboratory values; 5) at least 30 days of follow-up (FU) after surgery; 6) date of death recorded in the EMR or most recent follow-up available in case of survival until present day.

\section{Source of data and consent}

EMR review was approved by our institutional review board for retrospective chart analysis on patients who underwent surgery for spinal metastatic disease at our University tertiary care center. Informed consent for clinical research is systematically obtained from each patient after diagnosis and prior to surgery.

\section{Data collection and Outcome}

The following variables were assessed based on the factors needed as inputs to the SORG ML algorithm (Figure and Table 1):[16] primary tumor histology (based on groupings by Katagiri et al.),[23] Eastern Cooperative Oncology Group [ECOG] performance status,[24] American Spinal Injury Association (ASIA) Impairment Scale,[25] preoperative presence of any Charlson comorbidity other than metastatic disease,[26] presence of visceral metastases (metastases in liver or lung), presence of brain metastases, previous systemic therapy, three or more spine metastases, body mass index (kilograms per meter squared $[\mathrm{kg} / \mathrm{m} 2]$ ), hemoglobin (grams per deciliter $[\mathrm{g} / \mathrm{dL}]$ ), platelet count (x103/mL), absolute lymphocyte count (x103/mL), absolute neutrophil count (x103/ $\mu \mathrm{L})$, creatinine $(\mathrm{mg} / \mathrm{dL})$, international normalized ratio (INR), albumin $(\mathrm{g} / \mathrm{dL})$, and alkaline phosphatase (international units per liter [IU/L]).

Our primary outcome measure was postoperative survival and its correlation with survival prediction tools: the SORG nomogram, SORG ML algorithm,[16] and the Tokuhashi score (original 
and revised).[11,27] Survival as well as data contributing to the predictive survival metrics was determined through manual chart review. The date of last review was January $5^{\text {th }}, 2021$.

Data was missing in terms of inputs only for BMI for 4 patients (10\%). Data was also missing for the outcome measure for 1 year survival for 5 patients (12\%) due to recent operations without sufficient follow-up time. Otherwise, the data was complete.

\section{Statistical Analysis}

Continuous variables are reported with means and correspondent range or standard deviation (SD) and categorical variables with absolute number and percentages. Baseline patient and tumor characteristics were compared to the developmental cohort[16] and the validation cohort[18] (Table 2) with the Fisher exact test and the Mann-Whitney U test.

Individual predicted survival probabilities were calculated for each patient by inputting the variables in the machine-learning algorithm.[21] (https://sorgapps .shinyapps.io/spinemetssurvival/). Discrimination was measured using the c-statistic (which is also known as the area under the receiver operating characteristic curve [AUC] for binary classification) and visualized by plotting the receiver operating characteristic curve (Table 3). The AUC plots sensitivity against 1 - specificity for all potential cutoffs for a test and ranges from 0.5 (no better than chance) to 1.0 (perfect discriminative ability). We used bootstrap standard errors (1000 replications) to calculate 95\% confidence intervals of the AUC. Each prediction tool was considered as sufficiently accurate if the AUC was greater than 0.70.[28]

Receiver Operating Characteristic (ROC) curves were produced using JMP Statistical Software (JMP®, Version <15>. SAS Institute Inc., Cary, NC, 1989-2019) and allowed accuracy comparison between predictive tools.

The SORG ML algorithm, both for 3-months and 1-year, was determined to give a correct prediction in our ROC analysis if the predicted survival estimate was greater than or equal to 0.5 and the patient did in fact survive at 3-months or 1-year. Equally, if the estimate was less than 0.5, and the patient did not survive, then the prediction was determined correct. Otherwise, the prediction was determined to be incorrect.

For the Tokuhashi original score, a score of 0-5 predicted $\leq 3$ months of survival.[29] A score of 6-8 predicted $\leq 12$ months of survival. And a score of 9-12 predicted $>12$ months of survival. For the Tokuhashi revised score, a score of $0-8$ predicted $<6$ months survival. A score of 9-11 predicted $\geq 6$ months of survival. And a score of 12-15 predicted $\geq 12$ months of survival. Estimate scores for the Tokuhashi original and revised scores[27,11,29] were determined to be correct or incorrect based on whether the actual survival fell into the predicted range. 


\section{Results}

\section{Demographics}

The external validation cohort was composed of 40 patients operated for spinal metastatic disease. Mean age was 68 years (range 58 to 79). The most common primary cancer types were lung cancer $(n=10,25.0 \%)$, breast $(n=8,20.0 \%)$ and multiple myeloma $(n=4,10.0 \%)$. 90-day mortality rate was $8.0 \%$. 12-month mortality rate was $50.0 \% .40$ percent of patients were females (Table 2).

Baseline characteristics between the developmental and validation cohorts and our own cohort differed significantly on the following measures: age, absolute lymphocyte count, absolute neutrophil count, neutrophil-lymphocyte ratio, albumin, alkaline phosphatase, and creatinine.

\begin{tabular}{|c|c|c|c|c|c|}
\hline & & $\begin{array}{l}\text { Validation Cohort } \\
(n=200)\end{array}$ & $\begin{array}{l}\text { Developmental } \\
\text { Cohort }(n=732)\end{array}$ & $\begin{array}{l}\text { Geneva } \quad \text { Cohort } \\
(n=40)\end{array}$ & $p$-value \\
\hline Age & & $63.4(54.2-71.0)$ & $61(53-69)$ & $68.35(58.2-78.6)$ & $P=0.0013$ \\
\hline Female Sex & & $89(44.5)$ & $306(41.8)$ & $16(40)$ & \\
\hline BMI & & $26.3(23.3-29.7)$ & $26.3(23.1-29.7)$ & $25.5(20.8-30.2)$ & $P=0.1960$ \\
\hline \multicolumn{6}{|l|}{ ECOG } \\
\hline & 0 to 2 & $167(86.5)$ & $440(81.6)$ & $34(85)$ & \\
\hline & 3 to 4 & $26(13.5)$ & $99(18.4)$ & $6(15)$ & \\
\hline \multicolumn{6}{|l|}{$\begin{array}{l}\text { Primary Tumor } \\
\text { Histology }\end{array}$} \\
\hline & Group 1 & $37(18.5)$ & 219 (29.9) & $9(23)$ & \\
\hline & Group 2 & $72(36.0)$ & $254(34.7)$ & $6(15)$ & \\
\hline & Group 3 & $91(45.5)$ & $259(35.4)$ & $25(62)$ & \\
\hline Visceral Mets & & $127(63.5)$ & $252(34.4)$ & $10(25)$ & \\
\hline Brain Mets & & $30(15.0)$ & $81(11.1)$ & $5(12.5)$ & \\
\hline $\begin{array}{l}3 \text { or more spine } \\
\text { mets }\end{array}$ & & $99(49.5)$ & $404(55.2)$ & $18(45)$ & \\
\hline $\begin{array}{l}\text { Previous } \\
\text { Systemic } \\
\text { Therapy }\end{array}$ & & $111(55.5)$ & $418(57.1)$ & $23(57.5)$ & \\
\hline $\begin{array}{l}\text { Other Charlson } \\
\text { Comorbidity }\end{array}$ & & $121(60.5)$ & $441(60.7)$ & $20(50)$ & \\
\hline \multicolumn{6}{|l|}{ ASIA } \\
\hline & Normal (E) & $162(82.7)$ & $379(52.6)$ & $36(90)$ & \\
\hline & Impaired & $34(17.3)$ & $342(47.4)$ & $4(10)$ & \\
\hline
\end{tabular}




\begin{tabular}{|c|c|c|c|c|c|}
\hline & $(A-D)$ & & & & \\
\hline Hemoglobin & & $11.9(10.1-13.3)$ & $12.1(10.7-13.3)$ & $11.3(8.2-14.4)$ & $P=0.0821$ \\
\hline Platelet & & $263.0(196.8-334.8)$ & 259 (196-337) & $255.9(174.8-337)$ & $P=0.5706$ \\
\hline $\begin{array}{l}\text { Absolute } \\
\text { Lymphocyte }\end{array}$ & & $0.90(0.60-1.30)$ & $0.90(0.58-1.43)$ & $1.5(.5-2.5)$ & $P<0.0001$ \\
\hline $\begin{array}{l}\text { Absolute } \\
\text { Neutrophil }\end{array}$ & & $7.10(4.50-10.00)$ & $6.32(4.48-8.80)$ & $5.4(2.7-8.1)$ & $P=0.0005$ \\
\hline $\begin{array}{l}\text { Platelet } \\
\text { Lymphocyte } \\
\text { Ratio }\end{array}$ & & $282.1(185.9-493.0)$ & $281(173-461)$ & $249.2(70.3-428.1)$ & $P=0.2374$ \\
\hline $\begin{array}{l}\text { Neutrophil } \\
\text { Lymphocyte } \\
\text { Ratio }\end{array}$ & & $8.74(4.10-13.57)$ & $7.22(3.64-12.8)$ & $5.7(.2-11.2)$ & $P=0.0005$ \\
\hline Albumin & & $4.00(3.60-4.20)$ & $3.80(3.40-4.20)$ & $3.83(2.9-4.8)$ & $P=0.0220$ \\
\hline Alk Phos & & $102.5(77.0-141.5)$ & $94.5(73.0-140)$ & $126.2(17.7-234.7)$ & $P=0.0143$ \\
\hline Creatinine & & $0.80(0.60-0.90)$ & $0.80(0.69-1.00)$ & $.933(.591-1.275)$ & \\
\hline INR & & $1.07(1.01-1.15)$ & $1.10(1.00-1.10)$ & $1.05(.99-1.11)$ & $P=0.0960$ \\
\hline $\begin{array}{l}\text { 90-day } \\
\text { mortality }\end{array}$ & & $55(27.6)$ & $181(25.1)$ & $8(20)$ & \\
\hline $\begin{array}{l}\text { 1-year } \\
\text { mortality }\end{array}$ & & 124 (62.9) & $385(54.3)$ & $20(50)$ & \\
\hline
\end{tabular}

Table 2: Baseline characteristics and differences between the patients from the development data set[16,18] and the external validation data set.

\section{External validation and comparison to Tokuhashi}

The SORG ML algorithm for 3-month mortality prediction in spinal metastatic disease achieved an AUC of 0.87 . The SORG ML algorithm for 12-month mortality prediction in spinal metastatic disease achieved an AUC of 0.85. The SORG Nomogram had a similar predictive ability at 3-months and 1-year with AUC's of 0.87 and 0.76 respectively. These results showed excellent discriminative ability as compared with the Tokuhashi Original Score which achieved AUC's of 0.70 and 0.69 and the Tokuhashi Revised Score which had an AUC's of 0.65 and 0.71 for 3-months and 1-year respectively. (Table 3, Figures 2 and 3). 


\begin{tabular}{|l|l|lr|l|l|l|}
\hline Prediction & SORG & SORG & $\mathrm{ML}$ & Tokuhashi & Tokuhashi & P-value \\
timing & $\begin{array}{l}\text { nomogram } \\
\text { AUC } \\
\mathrm{Cl})\end{array}$ & $\begin{array}{l}\text { AUC } \\
\text { (9) }\end{array}$ & $(95 \%$ & $\begin{array}{l}\text { original AUC } \\
(95 \% \mathrm{Cl})\end{array}$ & $\begin{array}{l}\text { revised AUC } \\
(95 \% \mathrm{Cl})\end{array}$ & \\
\hline 3-months & 0.87 & 0.87 & 0.70 & 0.65 & $\mathbf{0 . 0 3 3}$ \\
\hline 12-months & 0.76 & 0.85 & 0.69 & 0.71 & $\mathbf{0 . 0 4 2}$ \\
\hline
\end{tabular}

Table 3: AUC (3- and 12-months) for the SORG nomogram, SORG classic algorithm, Tokuhashi score original and Tokuhashi revised, and $\mathrm{P}$ values from ROC analysis and linear regression. AUC, area under the curve; $\mathrm{CI}$, confidence interval.

Bold indicates significance (two-tailed P-value below 0.05).

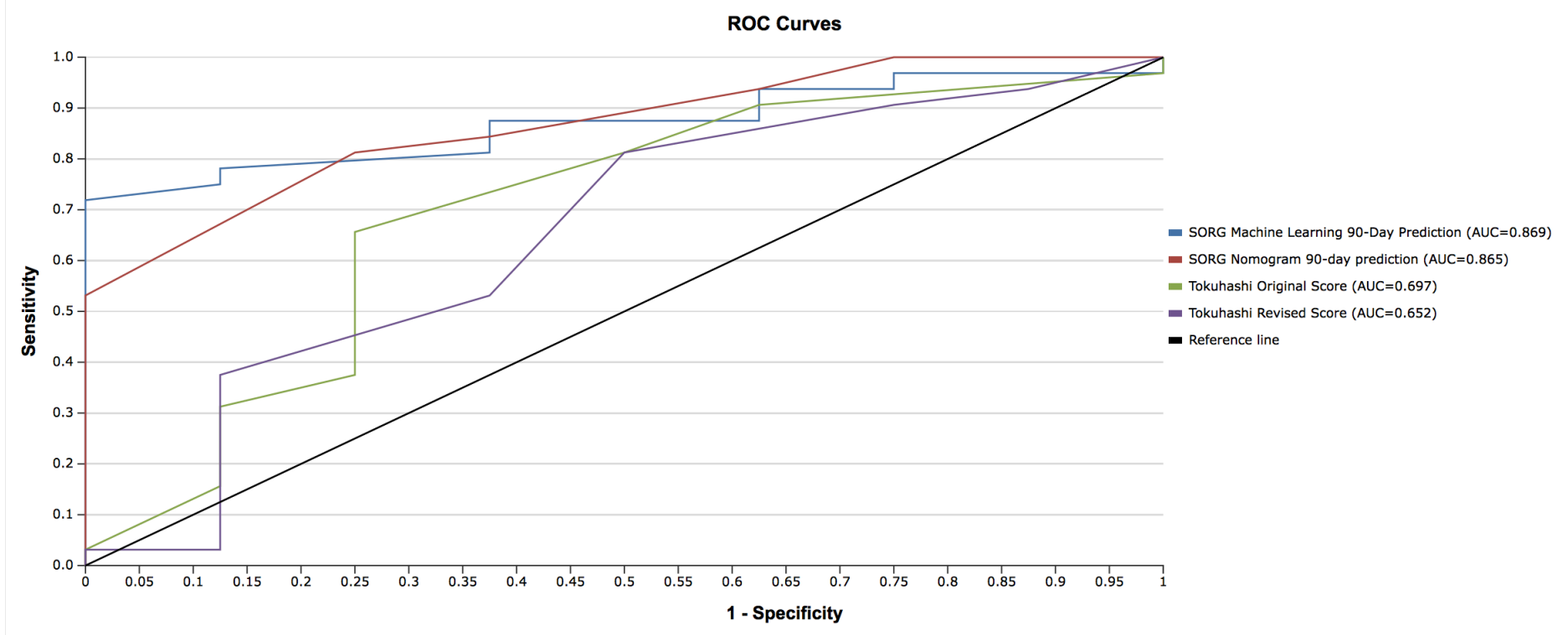

Figure 2: Receiver Operating Characteristic (ROC) Curve for 90-day predictions demonstrating the superiority of the SORG ML algorithm and Nomogram against the Tokuhashi original and revised scores. 


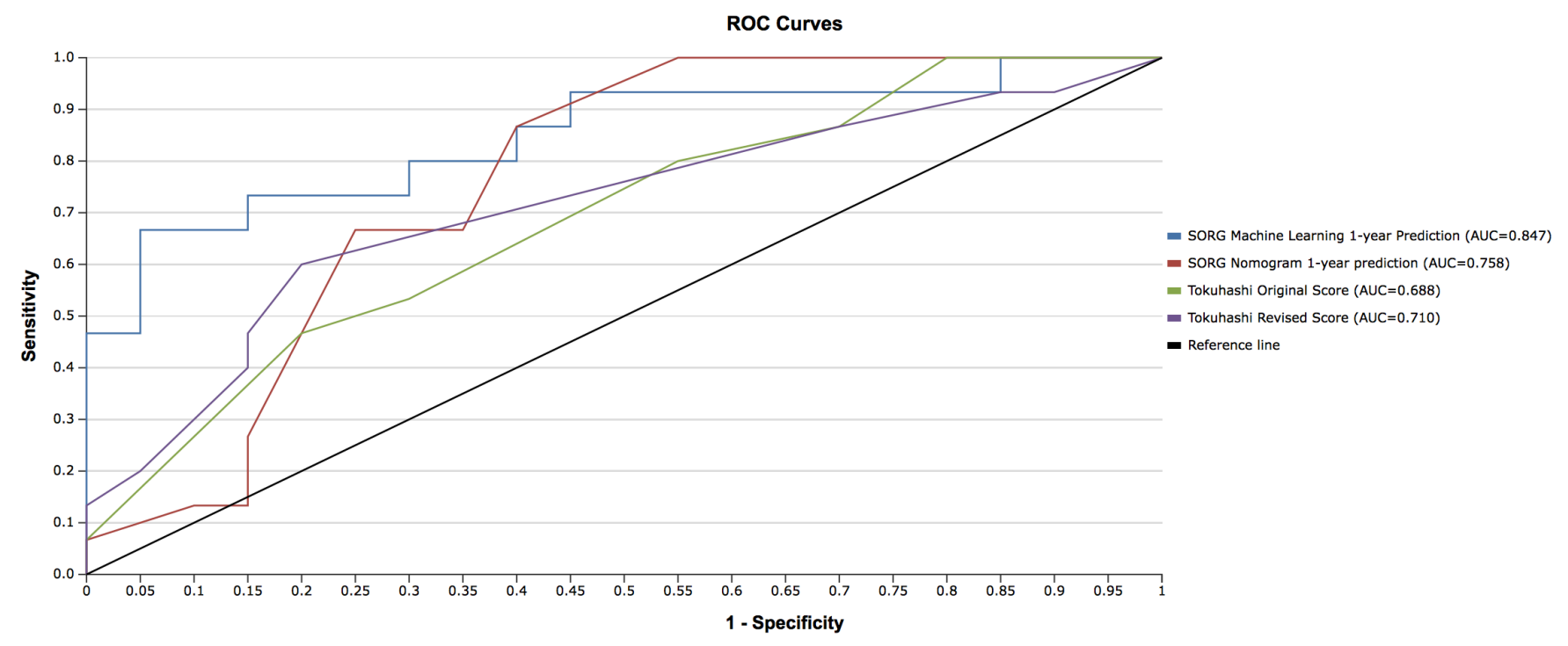

Figure 3: Same as the above. Superiority of the SORG ML and nomogram for 12-month prediction when compared with Tokuhashi scores.

The SORG ML delivered a correct prediction for 33 of 40 patients (80.5\%) for 3-months and was correct in 26 of 35 patients for 12-month predictions (74.3\%). The SORG nomogram was correct in 34 of 40 patients (85\%) at 3-months, and in 26 patients for 12-months predictions (74.3\%). In contrast, the Tokuhashi original score was correct for 19 patients (51\%). Finally, the Tokuhashi Revised Score was correct for 18 patients (46\%) (Figure 4). 


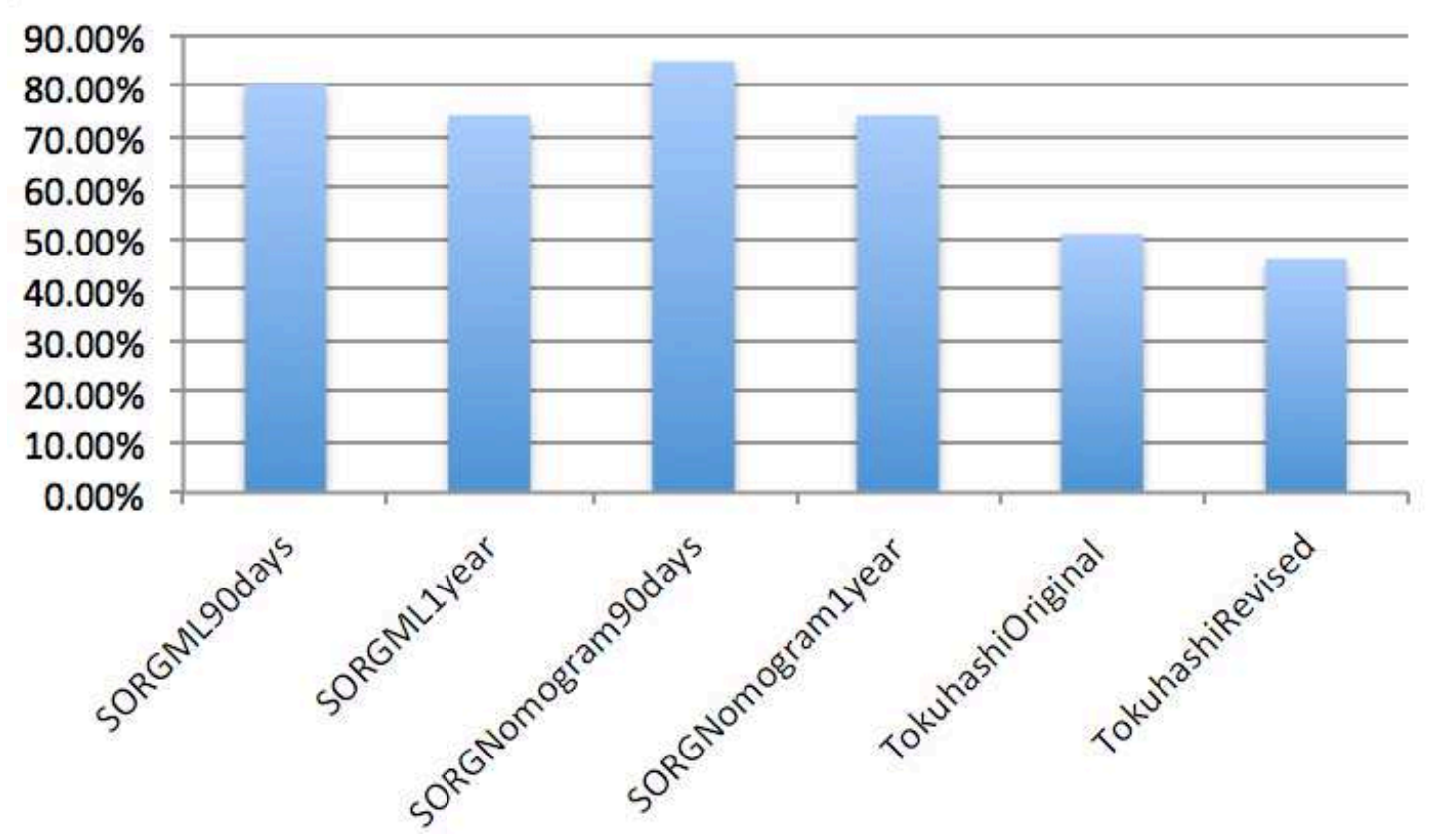

Figure 4: Percentage of correct predictions and decision for each score.

These results confirm our hypothesis that the SORG ML and SORG nomogram scores are better predictive tools than the Tokuhashi Original or Revised scores for spinal metastatic disease survival at 3 months and at 12-months. 


\section{Discussion}

Effective counseling of patients with metastatic spinal disease and their families in regard to surgical or conservative treatment options requires a reliable and validated scoring system to preoperatively predict the survival at key postoperative time-points such as 3-months and 12-months. It can be summarized as a balance between systemic disease burden and life expectancy against potential surgical complications and the weight of the rehabilitation period. The current state of affairs of this decision algorithm is based on multidisciplinary tumor board's discussions and still relies mainly in the revised Tokuhashi. This external population-based study was able to (1) provide newer and independent data confirming that the SORG ML and nomogram are better than the Tokuhashi classic and revised scores when it comes to predict survival at 3- and 12-months; (2) confirm a specificity higher than 70\% for both SORG ML and nomogram with only around 50\% for the Tokuhashi classic and revised; (3) point towards a different and more conservative decisions in at least $10 \%$ of the operated cases.

According to the TRIPOD guidelines,[22] algorithms should be repeatedly validated, for the assessment of possible performance inadequacies, among different independent populations. The SORG ML and classic algorithm were previously developed and externally validated but needed to face an international validation to see how they would perform outside the setting of a U.S. tertiary care center. This step is also essential in order to implement such a score in central European countries. The population of patients used in this study showed few significant differences from the validation and developmental cohort with regards to age and blood sample results.

Despite these differences, we have shown that the SORG ML algorithms showed very high performance in predicting 3- and 12-months mortality according to the receiver operating curves. In fact, the AUC in our international cohort actually outperformed the validation cohort already published ( 0.87 vs. 0.75 for 90 -day and 0.85 vs. 0.77 for 1-year).[17] The SORG nomogram also performed very well in our international cohort with an AUC of 0.87 for 90 -days and 0.76 for 1-year. These findings are even more encouraging when compared with the results from Nater et al. [10] that showed an AUC of 70 for 3-months and 0.78 for 12-months for the best predictive tool among nine different scoring systems or even from Paulino Pereira and Bongers et al.[20,18] These facts also mean that this study is the first to show a clear advantage of the SORG at one year, compared with the Tokuhashi.

This better discriminative power from both SORG ML and nomogram is also accompanied by a good overall calibration, despite the small size of the sample that prevented the realization of reliable calibration plots. Percentage of "good decisions" 
based on score predictive value (Figure 4) also show the same trend even though their interpretation shall be cautious due to the small sample size.

The objective evaluation showed that the utilization of the SORG ML or nomogram could have prevented 4 "bad surgical indications" in patients that died before 3-months. This represents $50 \%$ of the overall 3-month mortality rate of $20 \%$ and reinforces the belief that these tools are better than the ones currently used.

There are several limitations that must be acknowledged in order to appropriately contextualize these findings. We recognize that our sample size is limited after a recruitment time of 5-years from a single institution. A minimum of 200 events and non-events is recommended in order to obtain reliable calibration measurements, number that we weren't able to meet.[30] This sample size issue gains more importance when targeting a multivariate subpopulation analysis, for instance accuracy of predictions according to primary tumor histology. In order to improve the validity of these findings, we propose to continue recruiting patients into the cohort, and eventually to compare our findings with fellow European institutions, which could on the other hand had some population heterogeneity to the cohort and negatively influence the precision of future findings. Also the study design was retrospective. The baseline characteristics differed between the validation and the developmental cohort on some disease factors (laboratory findings and mean age). Also, patients that refused surgery were not included in this study which could have influenced survival periods and accuracy of algorithms.

This external validation cohort constitutes the first European test of the SORG ML and SORG nomogram predictive value and shows promising results that shall encourage the multidisciplinary teams to use these tools in a daily basis. Similar findings were already published in a Taiwainese cohort [31]. These algorithms showed a performance better than the currently utilized Tokuhashi revised, being more sensitive and specific in estimating 3- and 12-months survival in patients with metastatic spine disease. The utility and applicability of these tools in populations treated with different treatment modalities other than surgery remains to be determined.

\section{Conclusions}

Initial results from external validation of the SORG ML algorithm in an international patient cohort are very encouraging. Our findings contribute to the already published data on the superiority of the SORG ML algorithm and nomogram in predicting survival for patients with spinal metastatic disease in comparison with other existent models and support their utilization upfront as at least of the tools helping clinicians to decide for or against surgery. Further studies are still needed to consolidate the use of these algorithm or ML in larger patient samples, from prospective and 
multi-institutional trials. ML usage proved to be easy and allows for potential updates in the future.

Simple Summary: The purpose of this study is to validate both a nomo- gram and machine-learning algorithm produced by the Skeletal Oncology Research Group (SORG) at Harvard Medical School in an international co- hort of patients. The SORG nomogram and Machine Learning (ML) Algorithm provides preoperative survival estimation at 3 months and 1 year in spinal metastatic disease and helps in determining the appropriateness of surgical management. The analysis of data in our independent cohort shows a clear advantage in terms of predictive ability of the SORG ma- chine-learning algorithm and nomogram in comparison with the To- kuhashi scores. We conclude that the predictive ability of the SORG ML algorithm and nomogram is superior to currently used preoperative sur- vival estimation scores for spinal metastatic disease.

Funding: This research received no external funding.

Prior publishing in conference proceedings: This work has been published by the same authors in the conference proceedings of Brain and Spine, Volume 1, Supplement 1, 2021 [32].

Institutional Review Board Statement: EMR review was given ethical approval by the Geneva University Hospitals institutional review board for retrospective chart analysis on patients who underwent surgery for spinal metastatic disease at our University tertiary care center.

Informed Consent Statement: Informed consent for clinical research is systematically obtained from each patient after diagnosis and prior to surgery.

Conflicts of Interest: The authors declare no conflict of interest.

\section{References}

1. Taylor JW, Schiff D [2010] Metastatic epidural spinal cord compression. Semin Neurol 30 (3):245-253. doi:10.1055/s-0030-1255221

2. Sciubba DM, Petteys RJ, Dekutoski MB, Fisher CG, Fehlings MG, Ondra SL, Rhines LD, Gokaslan ZL [2010] Diagnosis and management of metastatic spine disease. A review. J Neurosurg Spine 13 (1):94-108. doi:10.3171/2010.3.Spine09202

3. Cole JS, Patchell RA [2008] Metastatic epidural spinal cord compression. Lancet Neurol 7 (5):459-466. doi:10.1016/s1474-4422(08)70089-9

4. L'esperance S, Vincent F, Gaudreault M, Ouellet J, Li M, Tosikyan A, Goulet S, oncologie Cdlédpe [2012] Treatment of metastatic spinal cord compression: cepo review and clinical recommendations. Current Oncology 19 (6):e478

5. Yoshihara H, Yoneoka D [2014] Trends in the surgical treatment for spinal metastasis and the in-hospital patient outcomes in the United States from 2000 to 2009. The Spine Journal 14 (9):1844-1849

6. Laufer I, Rubin DG, Lis E, Cox BW, Stubblefield MD, Yamada Y, Bilsky MH [2013] The NOMS framework: approach to the treatment of spinal metastatic tumors. Oncologist 18 (6):744-751. doi:10.1634/theoncologist.2012-0293

7. Sciubba DM, Goodwin CR, Yurter A, Ju D, Gokaslan ZL, Fisher C, Rhines LD, Fehlings MG, Fourney DR, Mendel E, Laufer I, Bettegowda C, Patel SR, Rampersaud YR, Sahgal A, Reynolds J, Chou D, Weber MH, Clarke MJ [2016] A Systematic Review of Clinical Outcomes and Prognostic Factors for Patients Undergoing Surgery for Spinal Metastases Secondary to Breast Cancer. 
8. Bouthors C, Prost S, Court C, Blondel B, Charles YP, Fuentes S, Mousselard HP, Mazel C, Flouzat-Lachaniette CH, Bonnevialle P, Saihlan F, the S [2020] Outcomes of surgical treatments of spinal metastases: a prospective study. Supportive Care in Cancer 28 (5):2127-2135. doi:10.1007/s00520-019-05015-5

9. Dea N, Versteeg AL, Sahgal A, Verlaan J-J, Charest-Morin R, Rhines LD, Sciubba DM, Schuster JM, Weber MH, Lazary A, Fehlings MG, Clarke MJ, Arnold PM, Boriani S, Bettegowda C, Laufer I, Gokaslan ZL, Fisher CG, Tumor obotAKF [2019] Metastatic Spine Disease: Should Patients With Short Life Expectancy Be Denied Surgical Care? An International Retrospective Cohort Study. Neurosurgery 87 (2):303-311. doi:10.1093/neuros/nyz472

10. Nater A, Tetreault LA, Kopjar B, Arnold PM, Dekutoski MB, Finkelstein JA, Fisher CG, France JC, Gokaslan ZL, Rhines LD, Rose PS, Sahgal A, Schuster JM, Vaccaro AR, Fehlings MG [2018] Predictive factors of survival in a surgical series of metastatic epidural spinal cord compression and complete external validation of 8 multivariate models of survival in a prospective North American multicenter study. Cancer 124 (17):3536-3550. doi:10.1002/cncr.31585

11. Tokuhashi Y, Matsuzaki H, Toriyama S, Kawano H, Ohsaka S [1990] Scoring system for the preoperative evaluation of metastatic spine tumor prognosis. Spine (Phila Pa 1976) 15 (11):1110-1113. doi:10.1097/00007632-199011010-00005

12. Tomita K, Kawahara N, Kobayashi T, Yoshida A, Murakami H, Akamaru T [2001] Surgical strategy for spinal metastases. Spine (Phila Pa 1976) 26 (3):298-306. doi:10.1097/00007632-200102010-00016

13. van der Linden YM, Dijkstra SP, Vonk EJ, Marijnen CA, Leer JW [2005] Prediction of survival in patients with metastases in the spinal column: results based on a randomized trial of radiotherapy. Cancer 103 (2):320-328. doi:10.1002/cncr.20756

14. Bollen L, van der Linden YM, Pondaag W, Fiocco M, Pattynama BP, Marijnen CA, Nelissen RG, Peul WC, Dijkstra PD [2014] Prognostic factors associated with survival in patients with symptomatic spinal bone metastases: a retrospective cohort study of 1,043 patients. Neuro Oncol 16 (7):991-998. doi:10.1093/neuonc/not318

15. Karhade AV, Thio Q, Ogink PT, Bono CM, Ferrone ML, Oh KS, Saylor PJ, Schoenfeld AJ, Shin JH, Harris MB, Schwab JH [2019] Predicting 90-Day and 1-Year Mortality in Spinal Metastatic Disease: Development and Internal Validation. Neurosurgery 85 (4):E671-e681. doi:10.1093/neuros/nyz070

16. Paulino Pereira NR, Janssen SJ, van Dijk E, Harris MB, Hornicek FJ, Ferrone ML, Schwab JH [2016] Development of a Prognostic Survival Algorithm for Patients with Metastatic Spine Disease. J Bone Joint Surg Am 98 (21):1767-1776. doi:10.2106/jbjs.15.00975

17. Karhade AV, Ahmed AK, Pennington Z, Chara A, Schilling A, Thio Q, Ogink PT, Sciubba DM, Schwab JH [2020] External validation of the SORG 90-day and 1-year machine learning algorithms for survival in spinal metastatic disease. Spine $\mathrm{J} 20$ (1):14-21. doi:10.1016/j.spinee.2019.09.003

18. Bongers MER, Karhade AV, Villavieja J, Groot OQ, Bilsky MH, Laufer I, Schwab JH [2020] Does the SORG algorithm generalize to a contemporary cohort of patients with spinal metastases on external validation? The Spine Journal. doi:https://doi.org/10.1016/j.spinee.2020.05.003

19. Ahmed AK, Goodwin CR, Heravi A, Kim R, Abu-Bonsrah N, Sankey E, Kerekes D, De la Garza Ramos R, Schwab J, Sciubba DM [2018] Predicting survival for metastatic spine disease: a comparison of nine scoring systems. Spine J 18 (10):1804-1814. doi:10.1016/j.spinee.2018.03.011

20. Paulino Pereira NR, McLaughlin L, Janssen SJ, van Dijk CN, Bramer JAM, Laufer I, Bilsky MH, Schwab JH [2017] The SORG nomogram accurately predicts 3- and 12-months survival for operable spine metastatic disease: External validation. J Surg Oncol 115 (8):1019-1027. doi:10.1002/jso.24620

21. Paulino Pereira NR, Janssen SJ, van Dijk E, Harris MB, Hornicek FJ, Ferrone ML, Schwab JH [2016] SORG Nomogram application. https://sorg-apps.shinyapps.io/spinemetssurvival/. Accessed 26.09.20202020

22. Collins GS, Reitsma JB, Altman DG, Moons KG [2015] Transparent Reporting of a multivariable prediction model for Individual Prognosis Or Diagnosis (TRIPOD): the TRIPOD Statement. Br J Surg 102 (3):148-158. doi:10.1002/bjs.9736

23. Katagiri H, Okada R, Takagi T, Takahashi M, Murata H, Harada H, Nishimura T, Asakura H, Ogawa H [2014] New prognostic factors and scoring system for patients with skeletal metastasis. Cancer medicine 3 (5):1359-1367 
24. Oken MM, Creech RH, Tormey DC, Horton J, Davis TE, McFadden ET, Carbone PP [1982] Toxicity and response criteria of the Eastern Cooperative Oncology Group. Am J Clin Oncol 5 (6):649-655

25. Kirshblum S, Waring W, 3rd [2014] Updates for the International Standards for Neurological Classification of Spinal Cord Injury. Phys Med Rehabil Clin N Am 25 (3):505-517, vii. doi:10.1016/j.pmr.2014.04.001

26. Charlson ME, Pompei P, Ales KL, MacKenzie CR [1987] A new method of classifying prognostic comorbidity in longitudinal studies: development and validation. J Chronic Dis 40 (5):373-383. doi:10.1016/0021-9681(87)90171-8

27. Tokuhashi Y, Matsuzaki H, Oda H, Oshima M, Ryu J [2005] A revised scoring system for preoperative evaluation of metastatic spine tumor prognosis. Spine (Phila Pa 1976) 30 (19):2186-2191. doi:10.1097/01.brs.0000180401.06919.a5

28. Forsberg JA, Wedin R, Bauer HC, Hansen BH, Laitinen M, Trovik CS, Keller JO, Boland PJ, Healey JH [2012] External validation of the Bayesian Estimated Tools for Survival (BETS) models in patients with surgically treated skeletal metastases. BMC Cancer 12:493. doi:10.1186/1471-2407-12-493

29. Tokuhashi Y, Uei H, Oshima M, Ajiro Y [2014] Scoring system for prediction of metastatic spine tumor prognosis. World J Orthop 5 (3):262-271. doi:10.5312/wjo.v5.i3.262

30. Van Calster B, McLernon DJ, van Smeden M, Wynants L, Steyerberg EW, Topic Group 'Evaluating diagnostic t, prediction models' of the Si [2019] Calibration: the Achilles heel of predictive analytics. BMC Med 17 (1):230. doi:10.1186/s12916-019-1466-7

31. Yang JJ, Chen CW, Fourman MS, Bongers MER, Karhade AV, Groot OQ, Lin WH, Yen HK, Huang PH, Yang SH, Schwab JH, $\mathrm{Hu} \mathrm{MH}$ [2021]. International external validation of the SORG machine learning algorithms for predicting 90-day and 1-year survival of patients with spine metastases using a Taiwanese cohort. Spine J. 2021 Feb 2:S1529-9430(21)00060-7. doi: 10.1016/j.spinee.2021.01.027. Epub ahead of print. PMID: 33545371.

32. Gregory Zegarek, Enrico Tessitore, Aria Nouri, Karl Schaller, Renato Gondar. Sorg algorithm to predict 3- and 12-month survival in metastatic spinal disease: A cross-sectional population-based retrospective study. Brain and Spine. Volume 1, Supplement 1. 2021. 100122. ISSN 2772-5294. https://doi.org/10.1016/j.bas.2021.100122. 